\title{
Peer Review of "Mass Testing With Contact Tracing Compared to Test and Trace for the Effective Suppression of COVID-19 in the United Kingdom: Systematic Review"
}

Milad Asgari Mehrabadi, BSc, MSc

Department of Electrical Engineering and Computer Science, University of California Irvine, Irvine, CA, United States

\section{Related Articles:}

Preprint: https://preprints.jmir.org/preprint/27254

Author Responses to Peer-Review Reports: https://med.jmirx.org/2021/2/e28744/

Published Article: https://med.jmirx.org/2021/2/e27254/

(JMIRx Med 2021;2(2):e28745) doi: 10.2196/28745

\section{KEYWORDS}

COVID-19; SARS-CoV-2; test and trace; universal testing; mass testing; contact tracing; infection surveillance; prevention and control; review

This is a peer-review report submitted for the paper "Mass Testing With Contact Tracing Compared to Test and Trace for the Effective Suppression of COVID-19 in the United Kingdom: Systematic Review.”

\section{Round 1 Review}

\section{General Comments}

This review paper [1] assessed the importance of mass testing in controlling the spread of COVID-19 in the United Kingdom.

\section{Specific Comments}

This is a great, comprehensive work; congratulations to the author. However, I have some suggestions:
1. The information provided in the Methods section is extra and should not be mentioned there. The Methods section covers the methodology of the study, not the background.

2. The references to the studies mentioned in the Results section do not follow the journal's requirements. Please kindly fix those.

3. For Table 1, my suggestion is to add more columns explaining the summary of the study in a structured format. For example, you can distribute the information you have in the description as number of participants, the country under study, etc.

4. Do not repeat the methodology in the Results section.

5. Headers in the Results section do not follow the journal's requirements.

6. Put abbreviations used in the paper at the end of the paper as well (follow journal style).

\section{Conflicts of Interest}

None declared.

\section{Reference}

1. Mbwogge M. Mass Testing With Contact Tracing Compared to Test and Trace for the Effective Suppression of COVID-19 in the United Kingdom: Systematic Review. JMIRx Med 2021 Apr 12;2(2):e27254 [FREE Full text] [doi: 10.2196/27254]

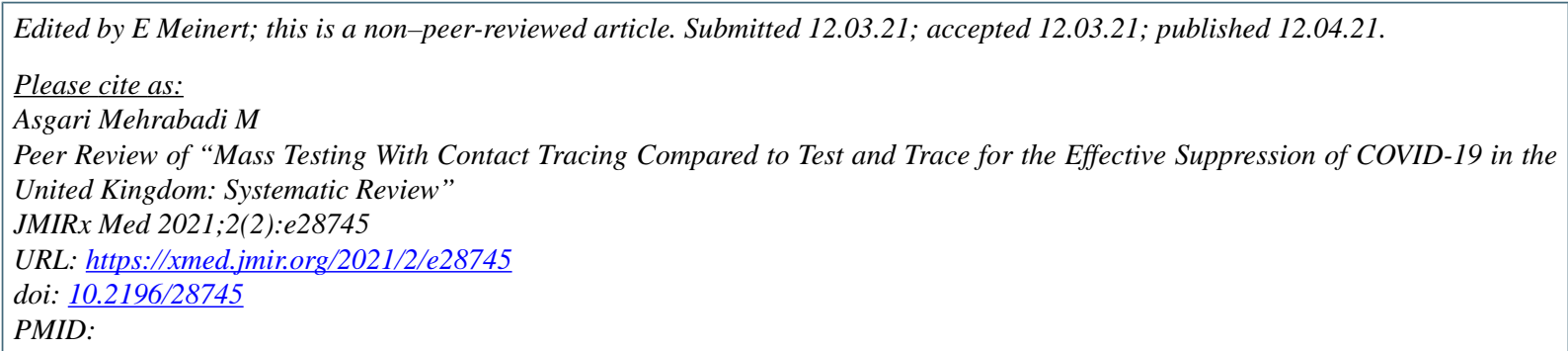


CMilad Asgari Mehrabadi. Originally published in JMIRx Med (https://med.jmirx.org), 12.04.2021. This is an open-access article distributed under the terms of the Creative Commons Attribution License (https://creativecommons.org/licenses/by/4.0/), which permits unrestricted use, distribution, and reproduction in any medium, provided the original work, first published in the JMIRx Med, is properly cited. The complete bibliographic information, a link to the original publication on http://med.jmirx.org/, as well as this copyright and license information must be included. 